\title{
Structural and electronic differences between deuterated and hydrogenated amorphous silicon
}

\author{
An Shih, Jiun-Lin Yeh, and Si-Chen Lee ${ }^{\mathrm{a})}$ \\ Department of Electrical Engineering, National Taiwan University, Taipei, Taiwan, Republic of China \\ T. R. Yang \\ Department of Physics, National Normal University, Taipei, Taiwan, Republic of China
}

(Received 13 September 1999; accepted for publication 3 May 2000)

\begin{abstract}
Both as-deposited and plasma-treated hydrogenated and deuterated amorphous silicon ( $a$-Si:H and $a-\mathrm{Si}: \mathrm{D})$ films are prepared by plasma-enhanced chemical vapor deposition. Their structural and electronic characteristics are studied and compared. It is found that the deuterium concentration of $a$-Si:D is higher than the hydrogen concentration of $a-\mathrm{Si}: \mathrm{H}$ in as-deposited samples, but is less in plasma-treated samples, which is consistent with the photoluminescence spectra. Besides, the proportionality constants relating the integrated stretching mode absorption to the concentrations of $\mathrm{Si}-\mathrm{D}$ and $\mathrm{Si}-\mathrm{H}$ bonds were determined, i.e., $1 \times 10^{20}$ for $\mathrm{Si}-\mathrm{D}$ and $6.9 \times 10^{19}$ for $\mathrm{Si}-\mathrm{H}$, by means of secondary ion mass spectrometry. (C) 2000 American Institute of Physics.
\end{abstract}

[S0021-8979(00)06815-8]

\section{INTRODUCTION}

Light-induced degradation of hydrogenated amorphous silicon $(a-\mathrm{Si}: \mathrm{H})$ materials and devices has been the subject of intensive studies, a phenomenon generally referred to as the Staebler-Wronski effect (SWE). ${ }^{1}$ It is generally agreed that recombination of excess electron-hole pairs generated by illumination creates metastable defects in the bulk of the materials. ${ }^{2}$ The defect states reduce the lifetime of the carriers and causes the degradation of the conductivity of $a-\mathrm{Si}: \mathrm{H}$. The possible involvement of hydrogen in the light-induced degradation process has motivated several workers to replace hydrogen with deuterium in the amorphous silicon and to investigate the stability issues. ${ }^{3-9}$ In this article, the hydrogen and deuterium concentrations of as-deposited and plasmatreated amorphous silicon films are measured quantitatively by means of secondary ion mass spectrometry (SIMS). The photoluminescence (PL) and infrared (IR) absorption spectra of as-deposited $a$-Si:H and $a$-Si:D are also measured and compared. Since it is convenient to determine the concentration of $\mathrm{Si}-\mathrm{H}$ and $\mathrm{Si}-\mathrm{D}$ bonds using infrared absorption spectra, the proportionality constants relating the integrated stretching mode absorption of the $\mathrm{SiH}_{n}$ and $\mathrm{SiD}_{n}(n=1$ or 2) molecules to their concentration are calibrated by means of SIMS.

\section{EXPERIMENTS}

Both $a$-Si:H and $a$-Si:D films were prepared by two different methods. In the first method, undoped $a$-Si:H ( $a$-Si:D) films were deposited on 7059 glass, twoside polished (100) crystalline silicon (for IR spectra) and

a) Author to whom correspondence should be addressed; electronic mail: sclee@cc.ee.ntu.edu.tw
$\mathrm{Al}_{2} \mathrm{O}_{3}$ (for PL) by plasma-enhanced chemical vapor deposition (PECVD) using a $\mathrm{SiH}_{4}+\mathrm{H}_{2}\left(\mathrm{SiD}_{4}+\mathrm{D}_{2}\right)$ mixture. The reason for using a two-side polished substrate was because the roughness of the substrate would alter the IR absorption amplitude of the $\mathrm{Si}-\mathrm{H}$ and $\mathrm{Si}-\mathrm{D}$ stretching mode $(>1000$ $\mathrm{cm}^{-1}$ ), but not the wagging mode. The deposition parameters were as follows: $\mathrm{rf}$ power density is $0.26 \mathrm{~W} / \mathrm{cm}^{2}$, substrate temperature $250^{\circ} \mathrm{C}$, chamber pressure $0.45 \mathrm{Torr}, \mathrm{SiH}_{4}\left(\mathrm{SiD}_{4}\right)$ flow rate $5 \mathrm{sccm}$, and $\mathrm{H}_{2}\left(\mathrm{D}_{2}\right)$ flow rate $2 \mathrm{sccm}$. The growth rates of $a-\mathrm{Si}: \mathrm{H}$ and $a-\mathrm{Si}: \mathrm{D}$ are 0.27 and $0.38 \mathrm{~nm} / \mathrm{s}$, respectively. In the second method, the $60 \mathrm{~nm}$ thick $a$-Si:H films deposited by PECVD were annealed at $550^{\circ} \mathrm{C}$ for $2 \mathrm{~h}$ in $\mathrm{N}_{2}$ ambient to expel all the hydrogen atoms from the films. Then the annealed films were treated separately by $\mathrm{H}_{2}$ and $\mathrm{D}_{2}$ plasma to passivate the dangling bonds until their electrical properties (dark conductivities and photoconductivities) were recovered. The duration was about $3 \mathrm{~h}$. The plasma-treated conditions were as follows: substrate temperature is $250^{\circ} \mathrm{C}$, chamber pressure 6 Torr, $\mathrm{H}_{2}\left(\mathrm{D}_{2}\right)$ gas flow rate $3 \mathrm{sccm}$, and power density $0.26 \mathrm{~W} / \mathrm{cm}^{2}$. The SIMS data were measured by Cameca $5 f$ in ultrahigh vacuum. The hydrogen and deuterium standard samples are purchased from Charles Evans Standard, which are prepared by ion implanting a known quantity of deuterium or hydrogen atoms into $c$-Si substrate. The infrared spectra were measured by a Bruker IFS $120 \mathrm{HR}$ IR spectrometer. Because the IR spectra of the $\mathrm{Si}-\mathrm{D}$ stretching mode is mixed with the absorption of the water vapor in air, the infrared spectra of all the samples were measured at room temperature in high vacuum. The resolution of the infrared spectra is $0.24 \mathrm{~cm}^{-1}$. The PL spectra were measured at $63 \mathrm{~K}$ with an Ar laser as the excitation source. The temperature refers to the temperature of the film surface, measured by a thermal detector on the surface of $\mathrm{Al}_{2} \mathrm{O}_{3}$. 


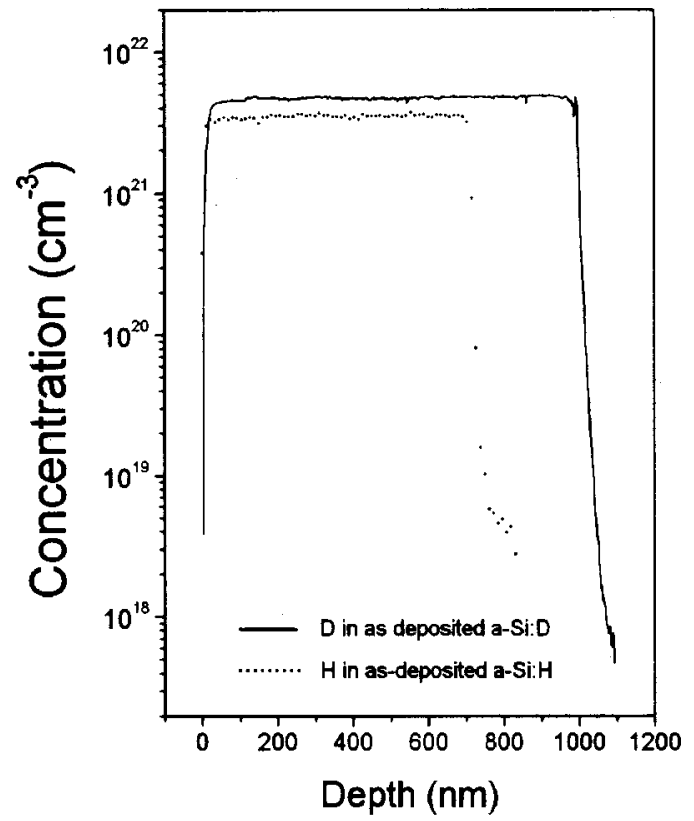

(a)

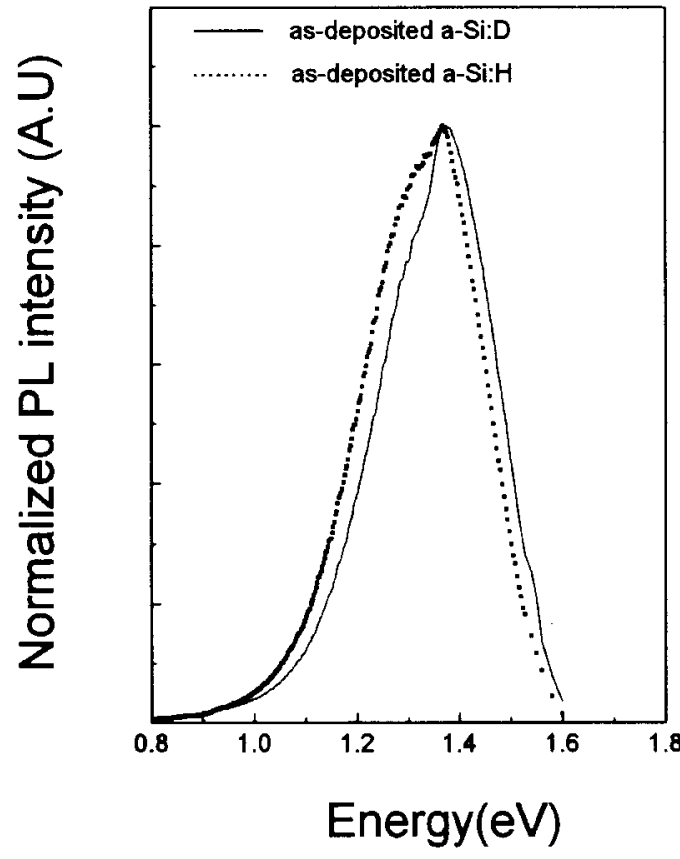

(b)

FIG. 1. (a) SIMS data of $690 \mathrm{~nm}$ thick $a$-Si:H film and $980 \mathrm{~nm}$ thick $a$-Si:D film. (b) Normalized PL spectra of the samples in (a). The solid and dotted lines represent the deuterium and hydrogen concentrations, respectively.

\section{RESULTS AND DISCUSSION}

Figure 1(a) displays the deuterium and hydrogen SIMS profiles of as-deposited Si:D samples, respectively. The deuterium concentration $\left(5.1 \times 10^{21} \mathrm{~cm}^{-3}\right)$ is higher than hydrogen concentration $\left(3.9 \times 10^{21} \mathrm{~cm}^{-3}\right)$, similar to the results in Ref. 5. But both the deuterium and hydrogen concentrations are lower than those in Ref. 5 due to the higher growth temperature. The higher deuterium concentration compared to the hydrogen content is likely due to the slower $\mathrm{D}_{2}$ elimi-

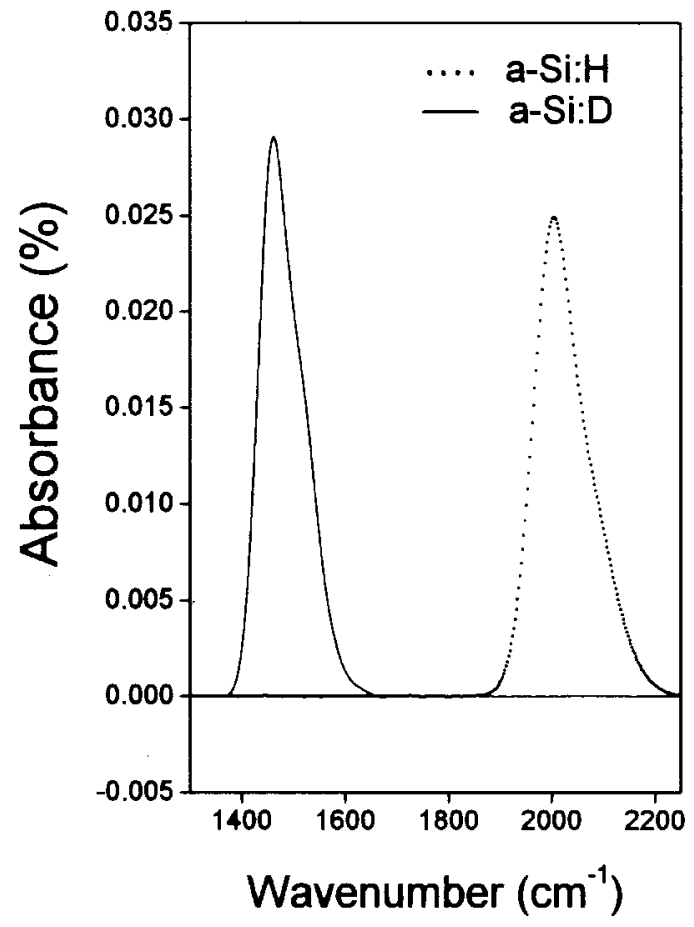

(a)

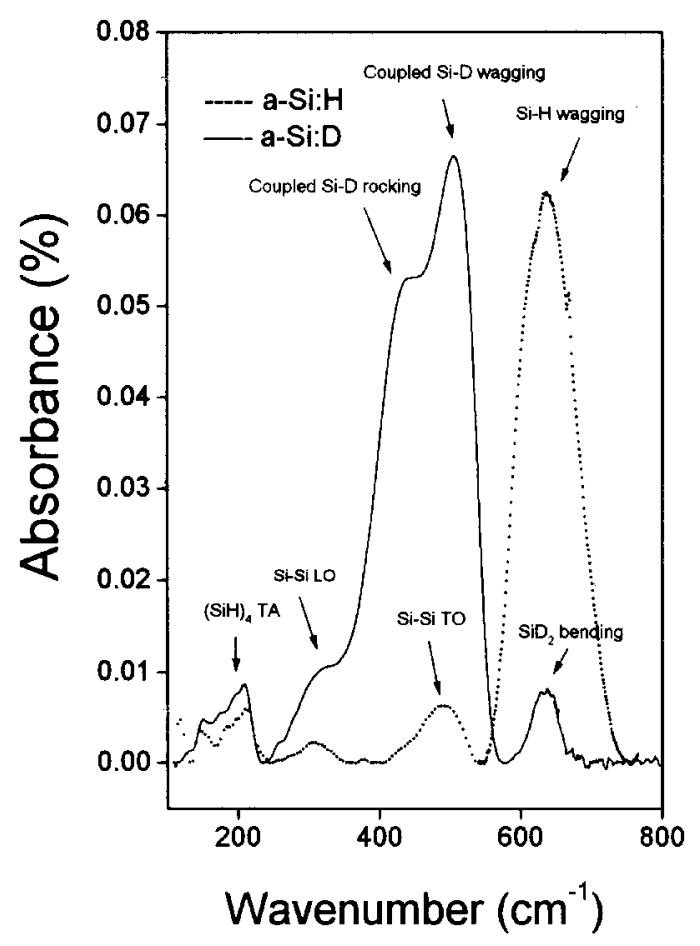

(b)

FIG. 2. Infrared absorption spectra of the $690 \mathrm{~nm}$ thick $a$-Si:H film and the $980 \mathrm{~nm}$ thick $a$-Si:D film in the range (a) $1300-2250 \mathrm{~cm}^{-1}$ and (b) $100-$ $800 \mathrm{~cm}^{-1}$ regime, the solid line represents the spectra of the $a-\mathrm{Si}: \mathrm{D}$ film and the dotted line represents the spectra of the $a-\mathrm{Si}: \mathrm{H}$ film.

nation rate $\left(2 \mathrm{Si}-\mathrm{D} \rightarrow 2 \mathrm{Si}-+\mathrm{D}_{2}\right)$ compared to the $\mathrm{H}_{2}$ elimination rate $\left(2 \mathrm{Si}-\mathrm{H} \rightarrow 2 \mathrm{Si}-+\mathrm{H}_{2}\right)$ from the film surface during growth. The slower $\mathrm{D}_{2}$ elimination rate can be attributed to the difference in the prefactor due to the mass difference 


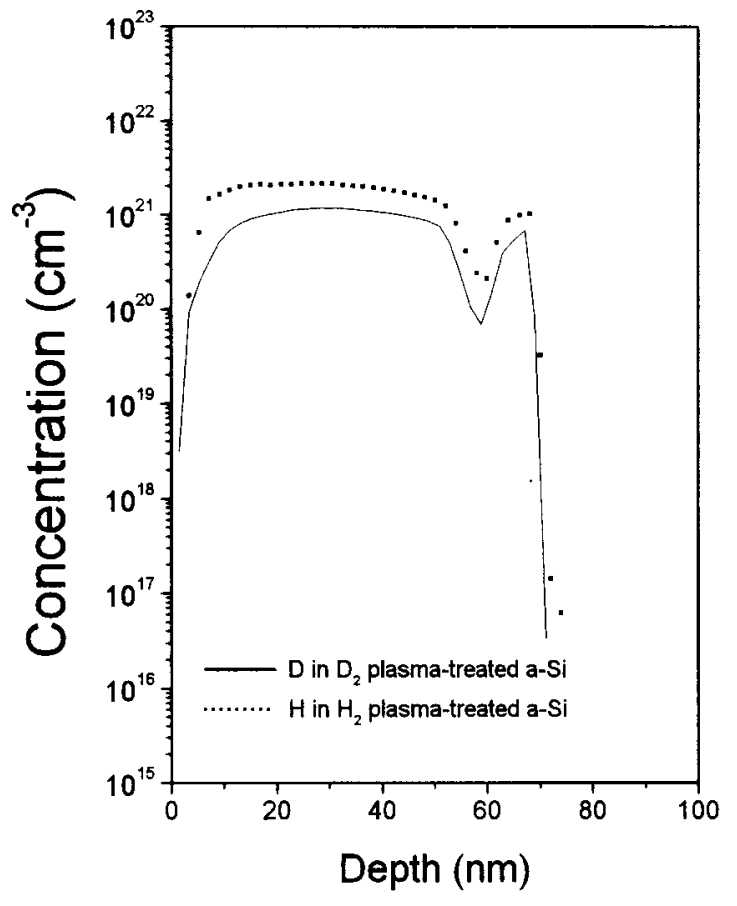

FIG. 3. SIMS data of the hydrogen and deuterium plasma-treated samples. The solid and dotted lines represent the deuterium and hydrogen concentrations, respectively.

as shown in Ref. 6. The growth rates of $a-\mathrm{Si}: \mathrm{H}$ and $a-\mathrm{Si}: \mathrm{D}$ are 0.27 and $0.38 \mathrm{~nm} / \mathrm{s}$, respectively. The low dilution growing condition and thus relatively high partial pressures of the source gases would suggest that a higher effective dilution is obtained for the $\mathrm{SiD}_{4}+\mathrm{D}_{2}$ combination than the $\mathrm{SiH}_{4}+\mathrm{H}_{2}$ combination, which leads to a higher electron temperature and thus a higher dissociation rate and a higher growth rate.

Figure 1(b) displays the PL spectra of as-deposited $a$-Si:H and $a$-Si:D samples. Apparently, the PL spectra of both $a-\mathrm{Si}: \mathrm{H}$ and $a-\mathrm{Si}: \mathrm{D}$ show two peaks at $63 \mathrm{~K}$. One peak of $a-\mathrm{Si}: \mathrm{H}$ centers at $1.38 \mathrm{eV}$ and the other at $1.29 \mathrm{eV}$, which are obtained by two Gaussian curve fittings. The PL peak of as-deposited $a$-Si:D centers at 1.4 and $1.31 \mathrm{eV}$, which is a little higher than those of $a$-Si:H film. The PL band occurs due to recombination of carriers trapped in the bands tails. The higher deuterium content compared to hydrogen, as shown in Fig. 1(a), would imply wider band gaps and make the PL peak of $a$-Si:D a little higher than the peak of $a-\mathrm{Si}: \mathrm{H}$.

Figure 2 shows the infrared absorption spectra of the 980 $\mathrm{nm}$ thick $a$-Si:D and $690 \mathrm{~nm}$ thick $a$-Si:H films deposited on two-side polished Si substrates, respectively. In Fig. 2(a), the absorption peak of $a-\mathrm{Si}: \mathrm{H}$ is found to locate at $2000 \mathrm{~cm}^{-1}, 10$ which is due to $\mathrm{Si}-\mathrm{H}$ stretching mode. ${ }^{11}$ A shoulder at 2090 $\mathrm{cm}^{-1}$ is attributed to the stretching mode of $\mathrm{SiH}_{2}{ }^{12}$ or monohydride in large voids. ${ }^{11}$ Similarly, the absorption peak of the $\mathrm{Si}-\mathrm{D}$ stretching mode is located at $1460 \mathrm{~cm}^{-1}$ and a shoulder appears at $1520 \mathrm{~cm}^{-1}$, which is the stretching mode of $\mathrm{SiD}_{2}$ or $\mathrm{Si}-\mathrm{D}$ in large voids. A measure of the amount of microstructure is then give by the ratio $R=I_{2090} /\left(I_{2090}\right.$ $\left.+I_{2090}\right)$. This is calculated to be 0.29 for the $a$-Si:H films. By analogy, the microstructure fraction of the $a-\mathrm{Si}: \mathrm{D}$, obtained from the modes at 1460 and $1520 \mathrm{~cm}^{-1}$, is 0.35 . This means that there are more microstructures in the $a$-Si:D film, conflicting with Ref. 5. The result is due to the fact that the growth rate of the $a-\mathrm{Si}: \mathrm{D}$ film is higher than that of the $a$-Si:H film. In Fig. 2(b), the main peak of the $a-\mathrm{Si}: \mathrm{H}$ film is located at $640 \mathrm{~cm}^{-1}$, which is due to the wagging mode of $\mathrm{Si}-\mathrm{H} .{ }^{12}$ A shoulder at $617 \mathrm{~cm}^{-1}$ is the rocking mode. ${ }^{10} \mathrm{~A}$ small peak at $490 \mathrm{~cm}^{-1}$ is due to $\mathrm{Si}-\mathrm{Si}$ TO mode vibration and the peak at $308 \mathrm{~cm}^{-1}$ is due to $\mathrm{Si}-\mathrm{Si} \mathrm{LA}$ mode vibration. ${ }^{13}$ The peak at $210 \mathrm{~cm}^{-1}$ is attributed to local modes of $(\mathrm{SiH})_{4}$ radicals which are pulled out of the TA band by hydrogen. ${ }^{13}$ For $a$-Si:D film, a small peak is found at $635 \mathrm{~cm}^{-1}$, which is attributed to the bending mode of $\mathrm{Si}-\mathrm{D}_{2}$. It is interesting to note that two large peaks appear at 506 and $441 \mathrm{~cm}^{-1}$ in the IR spectra of the $a$-Si:D film, which is very different from the $\mathrm{Si}-\mathrm{H}$ wagging mode. Because the $\mathrm{Si}-\mathrm{D}$ wagging mode is very close to the $\mathrm{Si}-\mathrm{Si} \mathrm{TO}$ mode vibration, which is located at $490 \mathrm{~cm}^{-1}$ as shown in Fig. 2(b), interaction between these two modes is expected. ${ }^{7,10}$ The interaction between the $\mathrm{Si}-\mathrm{Si} \mathrm{TO}$ mode and $\mathrm{Si}-\mathrm{D}$ wagging mode would push the wagging mode to higher energy, so the rocking mode and wagging mode is separated. Because the wagging mode of $\mathrm{Si}-\mathrm{D}$ overlaps the $\mathrm{Si}-\mathrm{Si} \mathrm{TO}$ mode, it is difficult to correctly integrate the wagging mode absorption of $\mathrm{Si}-\mathrm{D}$. Therefore, the stretching mode absorption must be used to calculate $\mathrm{Si}-\mathrm{D}$ concentration.

The hydrogen concentration in the samples can be related to IR spectra by the relationship ${ }^{10}$

$$
\begin{aligned}
N_{\mathrm{Si}-\mathrm{H}} & =\frac{c n \omega_{t}}{2 \pi^{2}} \frac{\mu}{e_{g}^{* 2}} \int \frac{\alpha(\omega)}{\omega} d \omega \\
& =A_{\mathrm{Si}-\mathrm{H}}^{s} \times \int \frac{\alpha(\omega)}{\omega} d \omega,
\end{aligned}
$$

where $c$ is the light velocity, $n$ the refractive index, $\mu$ the reduced mass of $\mathrm{Si}$ and $\mathrm{H}, \omega_{t}$ the peak absorption frequency, $e_{s}^{*}$ the effective charge of the $\mathrm{Si}-\mathrm{H}$ bond, and $\alpha$ the absorption coefficient. This relationship can also be applied to measure the $\mathrm{Si}-\mathrm{D}$ concentration. $A_{\mathrm{Si}-\mathrm{H}}^{s}$ is the proportionality constant relating the integrated stretching mode absorption to the concentrations of $\mathrm{Si}-\mathrm{H}$ bonds. Similarly, $A_{\mathrm{Si}-\mathrm{D}}^{S}$ is the proportionality constant of $\mathrm{Si}-\mathrm{D}$ bonds to integrated $\mathrm{Si}-\mathrm{D}$ absorption spectra. By inserting measured IR spectra and SIMS data to Eq. (2), the averaged values for $A_{\mathrm{Si}-\mathrm{H}}^{s}$ and $A_{\mathrm{Si}-\mathrm{D}}^{s}$ can be determined to be $A_{\mathrm{Si}-\mathrm{H}}^{s}=6.9 \times 10^{19}$ and $A_{\mathrm{Si}-\mathrm{D}}^{s}$ $=1 \times 10^{20}$. The value of $A_{\mathrm{Si}-\mathrm{D}}^{s}$ is about 1.4 times as that of $A_{\mathrm{Si}-\mathrm{H}}^{s}$. This ratio is consistent with Eq. (1), since the $\omega_{t} \mu$ value of $\mathrm{Si}-\mathrm{D}$ stretching mode is $\sqrt{2}$ times larger, whereas other parameters are the same as those of a $\mathrm{Si}-\mathrm{H}$ stretching mode. The value of $A_{\mathrm{Si}-\mathrm{H}}^{s}$ is different from the value proposed by Ref. 14, which is $1.1 \times 10^{20} \mathrm{~cm}^{-2}$. The difference might come from the substrate and SIMS calibrated standard samples. The surface morphology of the substrate would alter the IR absorption amplitude of the stretching mode, so the double polished crystal silicon substrate was used in our measurement. Besides, because ion implantation is a wellestablished technology, the SIMS calibration is precise.

Figure 3 shows the deuterium and hydrogen SIMS profiles of plasma-treated $a$-Si:H and $a$-Si:D samples, respectively. The dip near the $a$-Si:H(D)/glass interface may be 
caused by the charge accumulation due to sputtering close to the insulating substrate. Both the hydrogen concentration $\left(2.1 \times 10^{21} \mathrm{~cm}^{-3}\right)$ and deuterium concentration (1.1 $\times 10^{21} \mathrm{~cm}^{-3}$ ) are lower than the hydrogen and deuterium concentrations of as-deposited samples. The lower deuterium concentration compared to the hydrogen content in plasmatreated samples is due to the lower diffusion rate because of its heavier mass. Because the hydrogen and deuterium concentration are too small, the PL spectra of these two samples cannot be measured. From the quantum well model, ${ }^{15}$ the low-energy gap $a$-Si region forms the valley (well), and the microvoids containing $\mathrm{SiH}_{x}$ or $\mathrm{SiD}_{x}$ form the mountains (barriers). Decreasing the deuterium content corresponds to the shrinkage of the size and the number of $\mathrm{SiD}_{x}$ mountains, which tends to shrink the barrier region and the quantum confinement effect. Therefore, there are more leaking channels for the carriers in $a$-Si:D film in the confined state to percolate to the $a$-Si cluster region, which leads to a higher field-effect mobility in plasma-treated $a$-Si:D TFT. ${ }^{8,9}$

\section{CONCLUSION}

The deuterium and hydrogen concentration of asdeposited and plasma-treated samples have been studied quantitatively by means of SIMS. The deuterium concentration is more than the hydrogen concentration in as-deposited samples, which is consistent with the PL spectra. But the deuterium concentration is less than the hydrogen concentration in plasma-treated samples, which might account for the higher field-effect mobility in the deuterium plasma-treated amorphous silicon TFT. Besides, the proportionality constants relating to the integrated absorption spectra of the $\mathrm{Si}-\mathrm{D}$ and $\mathrm{Si}-\mathrm{H}$ stretching modes and the concentrations $A_{\mathrm{Si}-\mathrm{H}}^{s}$ and $A_{\mathrm{Si}-\mathrm{D}}^{s}$ are calibrated by SIMS.

\section{ACKNOWLEDGMENT}

This work is supported by the National Science Council of the Republic of China under Contract No. NSC89-2215E-002-006.

${ }^{1}$ D. L. Staebler and C. R. Wronski, Appl. Phys. Lett. 31, 292 (1977).

${ }^{2}$ S. Guha, J. Yang, W. Czubatyj, S. J. Hudgens, and M. Hack, Appl. Phys. Lett. 48, 62 (1986).

${ }^{3}$ J. W. Lyding, K. Hess, and I. C. Kiziyalli, Appl. Phys. Lett. 68, 2526 (1996)

${ }^{4}$ G. Ganguly, S. Yamasaki, and A. Matsuda, Philos. Mag. B 63, 281 (1991).

${ }^{5}$ W. A. Nevin, H. Yamagushi, K. Asaoka, H. Nishio, and Y. Tawada, Appl. Phys. Lett. 59, 3294 (1991).

${ }^{6}$ G. Ganguly and A. Matsuda, J. Non-Cryst. Solids 164-166, 31 (1993).

${ }^{7}$ J. H. Wei, M. S. Sun, and S. C. Lee, Appl. Phys. Lett. 71, 1498 (1997).

${ }^{8}$ J. H. Wei and S. C. Lee, J. Appl. Phys. 85, 543 (1999).

${ }^{9}$ J. L. Yeh and S. C. Lee, Electron Device Lett. 58, 415 (1999).

${ }^{10}$ M. H. Brodsky, M. Cardona, and J. J. Cuomo, Phys. Rev. B 16, 3556 (1977).

${ }^{11}$ H. Wagner and W. Beyer, Solid State Commun. 48, 7 (1983).

${ }^{12}$ W. B. Pollard and G. Lucovsky, Phys. Rev. B 26, 3172 (1982).

${ }^{13}$ S. C. Shen, C. J. Fang, M. Cardona, and L. Genzel, Phys. Rev. B 22, 2913 (1980).

${ }^{14}$ R. V. Kruzelecky, D. Racansky, and S. Zukotynski, J. Non-Cryst. Solids 108, 115 (1989).

${ }^{15}$ M. H. Brodsky, Solid State Commun. 36, 55 (1980). 